\title{
Positive surgical margins and biochemical recurrence following minimally-invasive radical prostatectomy - An analysis of outcomes from a UK tertiary referral centre
}

\author{
Ashwin Sachdeva ${ }^{1,2} \mathbb{B}$, Rajan Veeratterapillay ${ }^{1}$, Antonia Voysey ${ }^{1}$, Katherine Kelly ${ }^{1}$, Mark I. Johnson¹,
} Jonathan Aning ${ }^{1}$ and Naeem A. Soomro ${ }^{1,2^{*}}$

\begin{abstract}
Background: Positive surgical margins are a strong prognostic marker of disease outcome following radical prostatectomy, though prior evidence is largely from a PSA-screened population. We therefore aim to evaluate the biochemical recurrence in men with positive surgical margins (PSM) after minimally-invasive radical prostatectomy (MIRP) in a UK tertiary centre.

Methods: Retrospective study of men undergoing laparoscopic or robotic-assisted radical prostatectomy between 2002 and 2014. Men with positive surgical margins (PSM) were identified and their biochemical recurrence (BCR) rate compared with men without PSM. The primary outcome measures were BCR rates and time to BCR. Cox regression was used to estimate adjusted hazard ratios for biochemical recurrence rate $(B C R)$, accounting for potential confounders.

Results: Five hundred ninety-two men were included for analysis. Pre-operative D'Amico risk stratification showed $37.5 \%, 53.3 \%$ and $9.3 \%$ of patients in the low, intermediate and high-risk groups, respectively. On final pathological analysis, the proportion of patients with local staging pT2, pT3a and pT3b was $68.8 \%, 25.2 \%$ and $6.1 \%$ respectively. Overall positive margin rate was $30.6 \%$. On multivariate analysis, the only pre-operative factor associated with PSM was age $>65$ years. Patients with PSM were more likely to have higher tumour volume and more advanced pathological local stage. The BCR rate was $10.7 \%$ in margin-positive patients and $5.1 \%$ in margin-negative patients, at median 4.4-year follow-up. Upon multivariate analysis, high pre-operative PSA and high Gleason group were the only significant predictors of $B C R(P<0.05)$.
\end{abstract}

Conclusions: In comparison to patients with negative surgical margins, those with PSM do not translate into worse medium-term oncological outcomes in the majority of cases amongst our cohort. We found that high preoperative PSA and high Gleason group were the only significant predictors of BCR.

\section{Background}

Surgical margin status at pathological analysis after radical prostatectomy for prostate cancer is a key metric to define the oncological adequacy of prostate resection [1]. With active surveillance considered the primary management option for low-risk prostate cancer, radical

\footnotetext{
* Correspondence: naeem.soomro@nuth.nhs.uk

'Department of Urology, Freeman Hospital, Newcastle-upon-Tyne Hospitals NHS Foundation Trust, Newcastle-upon-Tyne, UK

${ }^{2}$ Northern Institute for Cancer Research, Newcastle University,

Newcastle-upon-Tyne, UK
}

prostatectomy (RP) is increasingly being used for intermediate or high-risk patients, as part of multi-modal therapy [2]. Positive surgical margin (PSM) rates have been associated with RP for higher-risk disease with reported incidence between 11-48\% [1-3]. PSM has been highlighted as a risk factor for disease progression after surgery and, as such, margin status has been incorporated as a component of multiple prostate cancer outcome prediction models [4-6]. 
In contemporary practice, patients with the finding of PSM alone at RP can be managed with PSA surveillance, adjuvant or salvage radiotherapy [7] or entered into clinical trials (for example RADICALS) [1, 4]. For patients with biochemical relapse (BCR) following RP, the European Association of Urology advises the use of salvage radiotherapy with at least 66Gy at a PSA level of $<0.5 \mathrm{ng} / \mathrm{ml}[8]$.

In a recent report regarding contemporary MIRP in the UK, the authors reported a trend towards increasing use of MIRP amongst patients with high risk disease, but with a high positive surgical margin rate of $33.6 \%$ amongst patients with pT3 disease [9]. However, longerterm oncological outcome data following MIRP in the UK are lacking. Furthermore, only a small percentage of patients in the UK are diagnosed with prostate cancer by PSA screening [10], in comparison to the widespread adoption of routine PSA screening in USA and some European countries [11]. Therefore, oncological outcomes of RP in a relatively unscreened UK population may be hypothesised to vary from those previously reported for screened cohorts.

In this report we describe the PSM rates in a consecutive series of patients undergoing minimally invasive radical prostatectomy at a large UK tertiary referral centre. We explore the factors predicting PSM and assess the medium term oncological outcomes as regards to biochemical recurrence rates.

\section{Methods}

\section{Study population}

Following approval by the local audit and research department, consecutive patients undergoing minimally invasive radical prostatectomy (MIRP - laparoscopic or robotic assisted) at our institution (between January 2002 and April 2014) were identified from a departmental database. Excised specimens underwent centralised pathological review. Patients undergoing open radical prostatectomy during this period were excluded. Retrospective review of their medical electronic records, histopathology data and biochemistry investigations was conducted. Data extracted included preoperative parameters (demographics, PSA, prostate biopsy Gleason score, clinical stage), operative details (technique and whether lymphadenectomy was performed) and postoperative radical prostatectomy pathology (presence of positive surgical, tumour Gleason score, tumour stage, tumour volume). Patients who had detectable PSA (ie $>0.1 \mathrm{ng} / \mathrm{mol}$ ) 12 weeks post-operatively, less than 12 months of follow-up or those for whom PSA follow-up data were unavailable, were excluded from this study.

\section{Follow-up and biochemical recurrence}

PSA follow-up data were captured. BCR was defined as undetectable PSA post radical prostatectomy, which subsequently rose to $\geq 0.2 \mathrm{ng} / \mathrm{mol}$. For patients with biochemical recurrence, the need and timing of adjuvant therapy (if any) was recorded.

\section{Statistical analysis}

Patient and disease characteristics between patients stratified by incidence of surgical margins and biochemical recurrence were compared using the Chi square test. Student's T test was used to compare means and MannWhitney $U$ test was used to compare medians. Potential co-variates including age, pre-operative PSA, Gleason score, and tumour volume, were included in a Cox regression model to estimate adjusted hazard ratios for positive surgical margins and biochemical recurrence. Kaplan-Meier survival curves were built using the time of biochemical recurrence as a failure event. A false discovery rate adjustment was applied for multiple comparisons. Results were deemed to be statistically significant if $\mathrm{p}$ value was less than 0.05 .

\section{Results}

The overall positive surgical margin rate was $30.6 \%$

In total 592 men underwent minimally invasive radical prostatectomy (MIRP) between 2002 and 2012. Median age at MIRP was 63 years (IQR 58-67 years). Median PSA at diagnosis was $7.9 \mathrm{ng} / \mathrm{ml}$ (IQR $5.7-11.8 \mathrm{ng} / \mathrm{ml}$ ) and median follow-up was 52.8 months (IQR 25.0-73.6 months). Demographic data is summarised in Table 1. Pre-operative D'Amico risk stratification noted $37.5 \%$ of patients in the low-risk group, $53.3 \%$ in the intermediate-risk group and 9.3\% in the high-risk group. 393 patients underwent laparoscopic RP (LRP) and 199 underwent roboticassisted RP (RARP). On final pathological analysis, the proportion of patients with local staging pT2, pT3a and pT3b was $68.8 \%, 25.2 \%$ and $6.1 \%$ respectively. Lymph node sampling was performed on $41.7 \%$ patients (247 of 592), of whom 19 patients $(8.0 \%)$ had evidence of lymph node involvement. Positive surgical margins (PSM) were identified in 181/592 (30.6\%) excised pathological specimens.

\section{PSM was associated with older age but not biopsy \\ Gleason score}

On univariate analysis (Table 1), the only preoperative factors associated with PSM were patient age >65years and PSA $>10 \mathrm{ng} / \mathrm{ml}$. Patients with PSM were also more likely to have higher Gleason score on final pathology, higher tumour volume and more advanced pathological local stage. The overall PSM was marginally higher following RARP, as compared to LRP ( $36.2 \%$ vs $27.7 \%, p=0.05)$. There was no significant change in PSM over time (LRP: $p=0.5$; RARP: $p=0.4$ ).

On multivariate logistic regression (Table 2), key factors predictive of PSM were patient age $>65$ years (OR 2.11, 95\% CI 1.41-3.15), higher pT stage (pT3a OR 
Table 1 Patient \& disease characteristics overall, stratified by surgical margin status

\begin{tabular}{|c|c|c|c|c|}
\hline Variable & Patients with positive margins & Patients with negative margins & Overall & $p$ value \\
\hline $\mathrm{N}(\%)$ & $181(30.6)$ & $411(69.4)$ & 592 & \\
\hline \multicolumn{5}{|l|}{ Patient age at time of surgery } \\
\hline Under 65 years & $82(45.3)$ & $252(61.3)$ & $334(56.4)$ & \multirow[t]{2}{*}{0.009} \\
\hline 65 years and above & $99(54.7)$ & $159(38.7)$ & $258(43.6)$ & \\
\hline \multicolumn{5}{|l|}{ Pre-op PSA } \\
\hline $0.0-9.9$ & $103(57.9)$ & $276(68.3)$ & $379(65.1)$ & \multirow[t]{4}{*}{0.03} \\
\hline $10.0-19.9$ & $58(32.6)$ & $110(27.2)$ & $168(28.9)$ & \\
\hline 20.0 and above & $17(9.6)$ & $19(4.5)$ & $35(6.0)$ & \\
\hline Missing & 2 & 7 & 9 & \\
\hline \multicolumn{5}{|l|}{ Gleason score on biopsy } \\
\hline Group 1 (GS 2-6) & $81(44.8)$ & $191(46.5)$ & $272(46.0)$ & \multirow[t]{5}{*}{0.5} \\
\hline Group 2 (GS 3+4) & $74(40.9)$ & $165(40.2)$ & $239(40.4)$ & \\
\hline Group 3 (GS 4+3) & $20(11.0)$ & $35(8.5)$ & $55(9.3)$ & \\
\hline Group 4 (GS 8) & $3(1.7)$ & $16(3.9)$ & $19(3.2)$ & \\
\hline Group 5 (GS 9-10) & $3(1.7)$ & $4(1.0)$ & $7(1.2)$ & \\
\hline \multicolumn{5}{|l|}{ Pathological Gleason score } \\
\hline Group 1 (GS 2-6) & $26(14.4)$ & $117(28.5)$ & $143(24.2)$ & \multirow[t]{5}{*}{$<0.001$} \\
\hline Group 2 (GS 3+4) & $92(50.8)$ & $218(54.0)$ & $310(52.4)$ & \\
\hline Group 3 (GS 4+3) & $33(18.2)$ & $40(9.7)$ & $73(12.3)$ & \\
\hline Group 4 (GS 8) & $20(11.1)$ & $31(7.5)$ & $51(8.6)$ & \\
\hline Group 5 (GS 9-10) & $10(5.5)$ & $5(1.2)$ & $15(2.5)$ & \\
\hline \multicolumn{5}{|l|}{ Pathological tumour stage } \\
\hline pT2 & $89(49.2)$ & $318(77.4)$ & $407(68.8)$ & \multirow[t]{3}{*}{$<0.001$} \\
\hline рТ3а & $68(37.6)$ & $81(19.7)$ & $149(25.2)$ & \\
\hline pT3b & $24(13.3)$ & $12(2.9)$ & $36(6.1)$ & \\
\hline Lymph node involvement & $10(11.8)$ & $7(4.6)$ & $17(7.2)$ & 0.06 \\
\hline \multicolumn{5}{|l|}{ Tumour volume of excised specimen } \\
\hline Median (IQR) & $3.9(1.8-6.7)$ & $2.02(0.81-4.0)$ & $2.4(1.0-5.1)$ & $<0.001$ \\
\hline \multicolumn{5}{|l|}{ Surgical approach } \\
\hline LRP & $109(60.2)$ & $284(69.1)$ & $393(66.4)$ & \multirow[t]{2}{*}{0.05} \\
\hline RARP & $72(39.8)$ & $157(30.9)$ & 199 (33.6) & \\
\hline \multicolumn{5}{|l|}{ Post-operative PSA* } \\
\hline Biochemical recurrence (\%) & $15 / 140(10.7)$ & 18 of $350(5.1)$ & 33 of $490(6.7)$ & 0.045 \\
\hline Median time to $B C R$ (in months, IQR)* & $10.9(3.7-24.5)$ & $13.1(4.9-37.7)$ & $12.1(4.9-31.4)$ & 0.5 \\
\hline
\end{tabular}

*PSA data available for 532 of 592 patients. 490 patients had undetectable PSA post-operatively

2.69, 95\% CI 1.73-4.18; pT3b OR 6.35, 95\% CI 2.7714.57), larger tumour volume (OR 1.09, 95\% CI 1.031.16 ), and the use of a robotic-approach (OR 2.52, 95\% CI 1.18-5.37).

The biochemical recurrence rate in PSM was $10.7 \%$

PSA follow up data were available for 532 patients (89.9\% of the cohort, Fig. 1) at a median follow-up of 30.3 months $(16.0$ - 52.7). Of these, 42 patients had detectable PSA post-operatively and were therefore excluded. In comparison to patients with undetectable PSA, these 42 patients tended to have more aggressive disease (Additional file 1: Table S1).

The overall biochemical recurrence rate (BCR) was $6.7 \%$ with a median time to BCR of 13.3 (11.6-33.5) months. Comparing PSM and NSM, the BCR at median follow-up of 52.8 months (IQR 25.0-73.6 months) was $10.7 \%$ and $5.1 \%$ respectively (p 0.026, Fig. 2). There was no difference in time to BCR between patients with PSM and NSM with a median time to 
Table 2 Logistic regression results with 95\% Cl \& p values (what factors predict PSM)

\begin{tabular}{|c|c|c|c|c|c|c|}
\hline \multirow[b]{2}{*}{ Variable } & \multicolumn{3}{|c|}{ Univariate analysis } & \multicolumn{3}{|c|}{ Multivariate analysis } \\
\hline & OR & $95 \% \mathrm{Cl}$ & $p$ value & OR & $95 \% \mathrm{Cl}$ & $p$ value \\
\hline \multicolumn{7}{|l|}{ Year of procedure } \\
\hline 2002-2009 & 1.00 & - & - & 1.00 & - & - \\
\hline 2010-2012 & 1.15 & $0.76-1.73$ & 0.5 & 0.72 & 0.43-1.19 & 0.2 \\
\hline 2013-2014 & 1.25 & $0.79-1.96$ & 0.4 & 0.37 & $0.15-0.93$ & 0.03 \\
\hline \multicolumn{7}{|l|}{ Patient age at time of surgery } \\
\hline Under 65 years & 1.00 & - & - & 1.00 & - & - \\
\hline 65 years \& above & 1.89 & $1.33-2.70$ & $<0.001$ & 2.11 & $1.41-3.15$ & $<0.001$ \\
\hline \multicolumn{7}{|l|}{ Pre-op PSA } \\
\hline $0.0-9.9$ & 1.00 & - & - & 1.00 & - & - \\
\hline $10.0-19.9$ & 1.41 & $0.96-2.09$ & 0.2 & 1.05 & $0.67-1.65$ & 0.8 \\
\hline 20.0 and above & 2.53 & $1.26-5.10$ & 0.02 & 1.30 & $0.56-3.00$ & 0.5 \\
\hline \multicolumn{7}{|l|}{ Gleason score on biopsy } \\
\hline Group 1 (GS 2-6) & 1.00 & - & - & 1.00 & - & - \\
\hline Group 2 (GS 3+4) & 1.06 & $0.72-1.54$ & 0.8 & 0.75 & $0.48-1.17$ & 0.2 \\
\hline Group 3 (GS 4+3) & 1.35 & $0.73-2.47$ & 0.4 & 0.86 & $0.43-1.69$ & 0.6 \\
\hline Group 4 (GS 8) & 0.44 & $0.13-1.56$ & 0.3 & 0.22 & $0.05-0.90$ & 0.04 \\
\hline Group 5 (GS 9-10) & 1.77 & $0.39-8.08$ & 0.6 & 0.86 & $0.15-4.89$ & 0.9 \\
\hline \multicolumn{7}{|l|}{ Pathological tumour stage } \\
\hline pT2 & 1.00 & - & - & 1.00 & - & - \\
\hline рT3а & 3.00 & $2.01-4.47$ & $<0.001$ & 2.69 & $1.73-4.18$ & $<0.001$ \\
\hline pT3b & 7.15 & $3.44-14.85$ & $<0.001$ & 6.35 & $2.77-14.57$ & $<0.001$ \\
\hline Median tumour volume of excised specimen & 1.16 & $1.10-1.22$ & $<0.001$ & 1.09 & 1.03-1.16 & 0.005 \\
\hline \multicolumn{7}{|l|}{ Surgical modality } \\
\hline LRP & 1.00 & - & - & 1.00 & - & - \\
\hline RARP & 1.48 & $1.03-2.13$ & 0.08 & 2.52 & $1.18-5.37$ & 0.02 \\
\hline
\end{tabular}

592 MIRPs performed

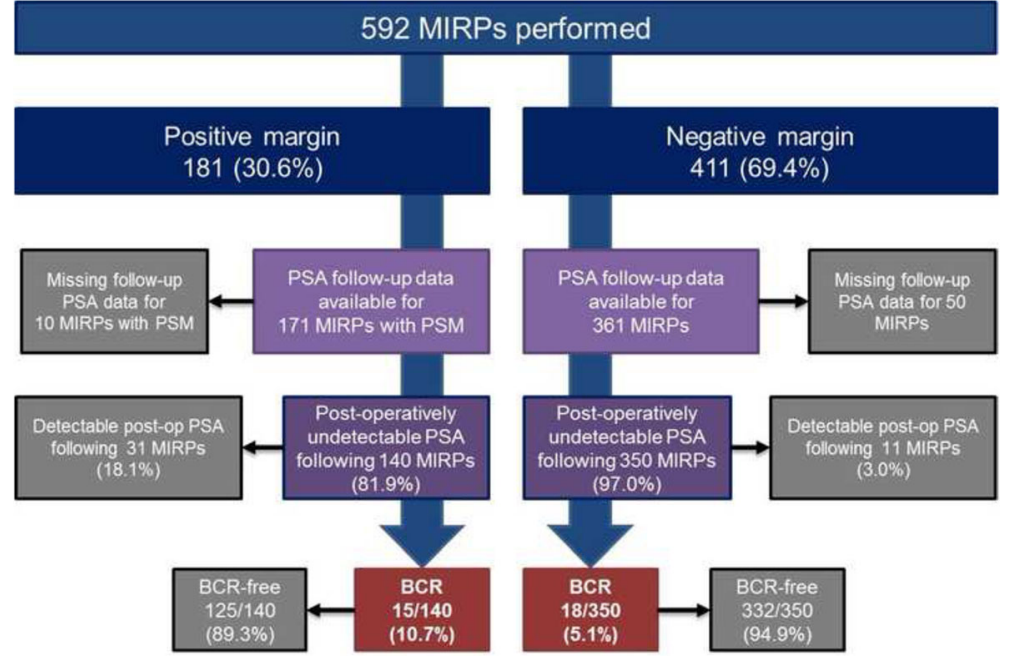

Fig. 1 Flow diagram of study population 


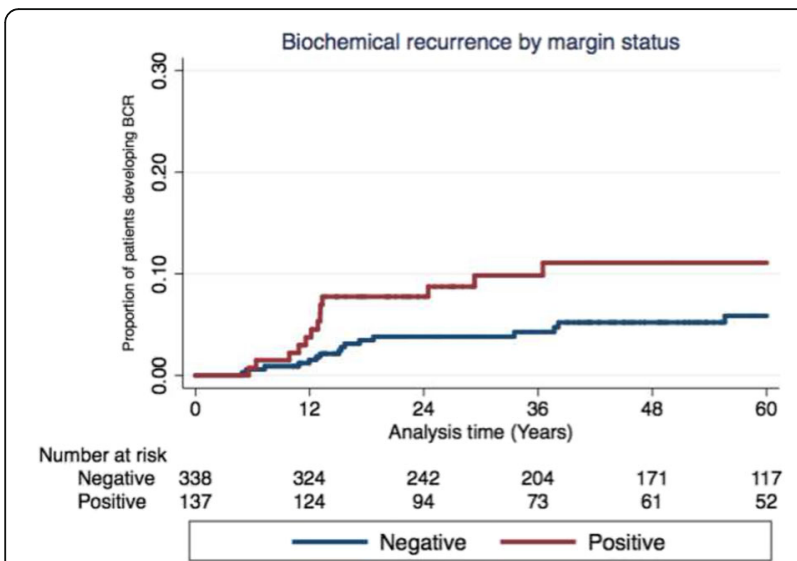

Fig. 2 Kaplan Meier survival analysis of time to biochemical recurrence stratified by margin status

BCR of 13.1 (10.8-29.3) months and 15.5 (12.0-37.7) respectively ( $p 0.49)$.

Upon univariate analysis, pre-operative PSA greater than $10 \mathrm{ng} / \mathrm{ml}$, larger tumour volume and PSM were associated with BCR (Table 3). However, upon multivariate Cox regression analysis to adjust for potential confounders, higher pre-operative PSA and higher Gleason group disease were associated with BCR (Additional file 1: Table S2). Of note, margin status was not associated with development of BCR.

\section{Discussion}

This is the largest reported single-centre UK series of oncological outcomes, including biochemical recurrence rates, following MIRP. The overall PSM in this cohort of 592 patients was $30.6 \%$. Upon adjustment for potential confounders, the only variables associated with greater incidence of PSM were older age at time of surgery, pT3 stage disease, higher tumour volume, and use of a RARP approach.

Comparative data indicate that the incidence of positive margins is equivalent among the open, laparoscopic, and RARP approaches [12]. A recent meta-analysis reported a $15 \%$ mean rate of PSMs in RARP series published between 2008 and 2011, with a range of $6.5-32 \%$ [3]. PSM rates in contemporary series range between 10.4 to $31.1 \%$. The largest report, by Wright et al, was based on a database study of 65,633 patients having radical prostatectomy. PSMs were reported in $21.2 \%$ of cases and were more common in pT3a than pT2 tumours ( $44 \%$ vs $18 \%, \mathrm{p}<0.001)$ and higher grade tumours $(28 \%$ vs $18 \%, \mathrm{p}<0.001)$ [13]. Reported RARP series have noted a PSM rate of $15.7-29.5 \%$ [9, 14-18]. Preoperative PSA, prostate volume on trans-rectal ultrasound, clinical $\mathrm{T}(\mathrm{cT})$ stage, and pathological stage (pT2 vs pT3) have been reported as independent predictors of the presence of any PSM, while cT stage and biopsy Gleason score have been reported as predictors of posterolateral PSM [14, 15].

From a UK perspective, of all 2,163 radical prostatectomies (54.6\% laparoscopic and 19.6\% RARP) entered in the British Association of Urological Surgeons database in 2011, the overall PSM was $42.3 \%$ with no difference between laparoscopic $(26.6 \%)$ and robotic $(22.5 \%)$ cases [19]. Our findings of PSM rates are comparable to published reports on minimally invasive prostatectomy. We do note however a higher PSM rate in patients undergoing robotic surgery $(36.2 \%)$ in our cohort and this may be representative of a learning curve effect. It is worth noting an increasing proportion of patients being offered surgery for high-risk disease. A recent study of robotic $\mathrm{RP}$ in this group was reported by Kang et al who reported a $25.1 \%$ PSM rate, and that higher tumour stage and volume were associated with PSM [20]. Furthermore, a recent UK series reported that accumulated experience with robotic RP was associated with a temporal decrease in PSM rate $(22.5 \%$ in $2005-2008$ vs $19.8 \%$ in 2013-15), despite an increase in the proportion of patients having surgery for higher risk disease [9].

In our study, patients with PSM were more likely to develop biochemical recurrence (10.7\%) versus those with negative margins (5.1\%). The median time to BCR for patients with PSM was 13.1 months. On multivariate analysis, factors predicting biochemical failure were high pre-operative PSA and higher pathological Gleason group at MIRP. The oncological implications of a positive surgical margin at radical prostatectomy are difficult to predict [1]. Nine large contemporary studies have investigated the impact of PSMs on biochemical recurrence rates, metastatic progression and prostate-cancer mortality (Table 4). Whilst all studies found PSMs to be associated with a higher risk of BCR, data on time to metastatic progression and death were less clear. Increased risk of PCa death was noted in men with positive compared with negative surgical margins, at 4.2 year [13] and 10 year follow-up [21]. However, this impact was fairly marginal relative to the impact of Gleason score and tumour stage on pathological assessment of the excised prostate [21]. From the literature, it is apparent that PSM increases the risk of disease recurrence but the range of risk and the time to event (death from prostate cancer) are very wide, depending mostly on the presence or absence of other risk modifiers. Even if the risk is real, competing causes of mortality may obscure the predictive value of PSMs for death due to PCa [1].

Biochemical recurrence is a marker of disease progression and associated with poor prognosis. Previous reports of BCR in patients with PSM are variable due to differing lengths of follow-up and surgical approach. Studies with patients predominantly undergoing open $\mathrm{RP}$ have reported a BCR rate of $26.7 \%$ at 6 years [22] to 
Table 3 Patient \& disease characteristics of patients with PSM, stratified by biochemical recurrence at end of study period

\begin{tabular}{|c|c|c|c|c|}
\hline Variable & BCR-free & $\mathrm{BCR}$ & All PSMs & $p$ value \\
\hline N (\%) & $125(89.3)$ & $15(10.7)$ & 140 & \\
\hline \multicolumn{5}{|l|}{ Patient age at time of surgery } \\
\hline Under 65 years & $60(48.0)$ & $7(46.7)$ & $67(47.9)$ & \multirow[t]{2}{*}{0.4} \\
\hline 65 years and above & $65(52.0)$ & $8(53.3)$ & $73(52.1)$ & \\
\hline \multicolumn{5}{|l|}{ Pre-op PSA } \\
\hline $0.0-9.9$ & $81(64.8)$ & $4(26.7)$ & $85(60.7)$ & \multirow[t]{3}{*}{0.003} \\
\hline 10.0-19.9 & $38(30.4)$ & $7(46.7)$ & $45(32.1)$ & \\
\hline 20.0 and above & $6(4.8)$ & $4(26.7)$ & $10(7.2)$ & \\
\hline \multicolumn{5}{|l|}{ Pathological Gleason score } \\
\hline Group 1 (GS 2-6) & $20(16.0)$ & 0 & $20(14.3)$ & \multirow[t]{5}{*}{0.4} \\
\hline Group 2 (GS 3+4) & $59(55.2)$ & $8(53.3)$ & $77(55.0)$ & \\
\hline Group 3 (GS 4+3) & $18(14.4)$ & $5(33.3)$ & $23(16.4)$ & \\
\hline Group 4 (GS 8) & $13(10.4)$ & $2(13.3)$ & $15(10.7)$ & \\
\hline Group 5 (GS 9-10) & $5(4.0)$ & 0 & $5(3.6)$ & \\
\hline \multicolumn{5}{|l|}{ Surgical approach } \\
\hline LRP & $75(60.0)$ & $10(66.7)$ & $85(60.7)$ & \multirow[t]{2}{*}{0.6} \\
\hline RARP & $50(40.0)$ & $5(33.3)$ & $55(39.3)$ & \\
\hline \multicolumn{5}{|c|}{ Tumour volume of excised specimen } \\
\hline Median (IQR) & $3.7(1.7-6.6)$ & $5.1(2.5-10.2)$ & $3.8(1.8-6.7)$ & $<0.001$ \\
\hline \multicolumn{5}{|l|}{ Pathological tumour stage } \\
\hline pT2 & $67(53.6)$ & $5(33.3)$ & $72(51.4)$ & \multirow[t]{3}{*}{0.4} \\
\hline рТ3а & $44(35.2)$ & $6(40.0)$ & $50(35.7)$ & \\
\hline pT3b & $14(11.2)$ & $4(26.7)$ & $18(12.9)$ & \\
\hline Lymph node involvement & $7(13.5)$ & $0(0.0)$ & $0(11.5)$ & 0.4 \\
\hline \multicolumn{5}{|l|}{ Margin location } \\
\hline Apex & $33(26.4)$ & $4(26.7)$ & $37(26.4)$ & \multirow[t]{4}{*}{0.4} \\
\hline Base & $23(18.4)$ & $1(6.7)$ & $24(17.1)$ & \\
\hline Multifocal & $19(15.2)$ & $5(33.3)$ & $24(17.1)$ & \\
\hline Other & $50(40.0)$ & $5(33.3)$ & $55(39.3)$ & \\
\hline \multicolumn{5}{|l|}{ Adjuvant therapy } \\
\hline Salvage radiotherapy & 12 of $41(29.3)$ & 10 of $14(64.1)$ & 22 of $55(40.0)$ & \\
\hline Radiotherapy \& hormones & 0 & 1 of $14(7.2)$ & 1 of $55(1.8)$ & \\
\hline Missing & 84 & 1 & 85 & \\
\hline
\end{tabular}

Note: Patients with detectable PSA or missing PSA data post-operatively were excluded

$54.3 \%$ at 10 years [21]. In contrast, shorter follow-up data is available for patients with PSM following MIRP, with a BCR rate ranging from $6.2 \%$ at 1 year [14] to $29.0 \%$ at 6.3 years [23]. A recent multi-institutional study reported outcomes of over 5000 patients following RARP and reported BCR rates of $14.1 \%$ at a median follow-up of 4.2 years [18]. Our results are within this range and, based upon previous data, it is likely that additional patients may go on to develop BCR at longer follow-up.
The choice of therapeutic strategy for patients with PSM remains controversial. Recent evidence suggests that adjuvant radiotherapy may lead to a 50-60\% reduction in the risk of PSA progression in men with pathologically advanced prostate cancer [24, 25]. However, not all men with PSMs are destined to have treatment failure and indeed the majority of men with isolated PSMs, with or without extra-prostatic extension, are cured after RP alone [1, 3]. Therefore, recommending adjuvant radiotherapy to all men with 


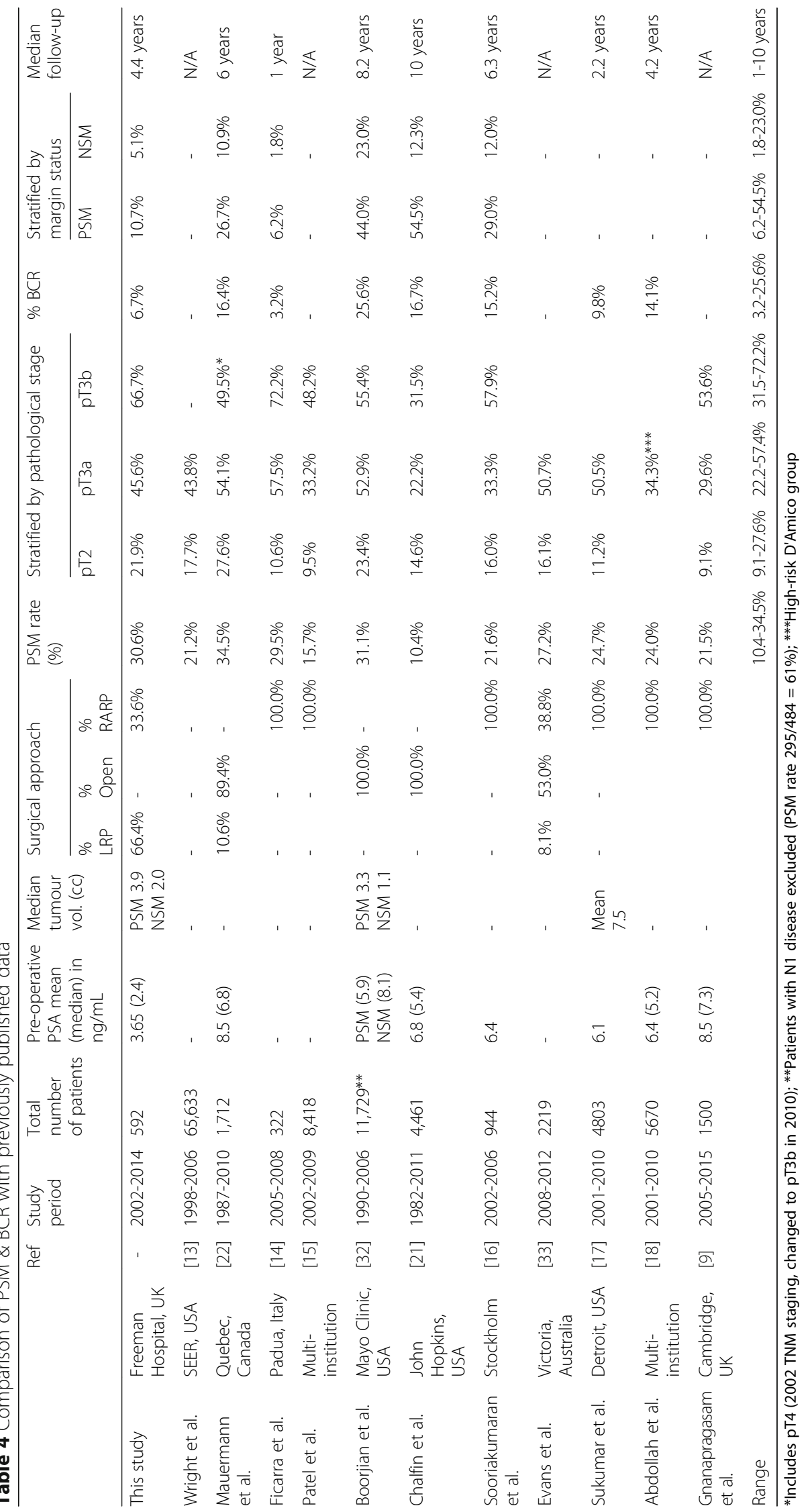


isolated PSMs should be done with caution especially when factoring in the added morbidity associated with radiotherapy treatment.

Detectable PSA following radical prostatectomy is often considered treatment failure. In our cohort, 7.9\% had detectable PSA post-operatively, and were excluded from subsequent analyses. These patients tended to have more aggressive disease and were more likely to have had positive surgical margins $(73.8 \%$ in patients with detectable PSA, vs $28.6 \%$ in patients with undetectable PSA post-operatively, $\mathrm{p}<0.001$, Additional file 1: Table S1). Similarly, Koulikov et al reported similar findings, whereby patients with low-detectable PSA $(>0.03$ and $<0.2 \mathrm{ng} / \mathrm{ml})$ and PSA velocity $>0.05 \mathrm{ng} /$ year, were more likely to have positive surgical margins and an increased incidence of biochemical recurrence [26]. These data suggest that men with low-detectable PSA post-prostatectomy may be divided into two groups based upon PSA velocity, those with stable PSA who do not often develop biochemical recurrence and those with unstable PSA who go on to develop biochemical recurrence. There is some evidence to suggest that this subgroup of patients may benefit from adjuvant radiotherapy [27].

There are some limitations to this study due to retrospective design and lack of PSA follow-up data for all patients. This is due to patients moving to their local units for follow-up. While previous reports and ours have predominantly focussed on reviewing the influence of pre-operative and surgical factors on long-term outcome, it is prudent to also note the potential impact of pathological features at the tumour margin. Pathological data regarding length of positive margin and grade pattern at the margin have previously been reported to predict BCR [28]. However, such data were not available for inclusion in our study. Moreover, molecular and biochemical features at tumour margins $[29,30]$ may also impact long term oncological outcomes, and subtyping positive margins based upon such features may provide a more effective method of identifying patients with PSM likely to benefit from personalised adjuvant therapies, as has been proposed for resection of other malignancies [31]. Lastly, this is a consecutive series of patients with an increasing volume of MIRPs performed each year. Therefore, it is difficult to accurately control for the effect of the learning curve. However, we adjusted for year of procedure, which may help adjust for this potential confounder to some degree. Interestingly, our data compares well to other series though we await the long-term maturation of this cohort.

\section{Conclusion}

In comparison to patients with negative surgical margins, those with PSM do not translate into worse medium-term oncological outcomes in the majority of cases amongst our cohort. We found that high pre-operative PSA and Gleason grade group were the only robust predictors of BCR.

\section{Additional file}

Additional file 1: Table S1. Patient \& disease characteristics overall, stratified by post-operative PSA status (detectable vs undetectable). Table S2. Multivariate evaluation of factors predicting BCR at 5-year follow-up using Cox regression. Results are reported as adjusted hazard ratios, with $95 \%$ confidence intervals. (DOCX $20 \mathrm{~kb}$ )

\section{Abbreviations}

BCR: Biochemical recurrence; LRP: Laparoscopic radical prostatectomy; MIRP: Minimally-invasive radical prostatectomy; NSM: Negative surgical margin; PSA: Prostate specific antigen; PSM: Positive surgical margin; RARP: Robotic-assisted radical prostatectomy

\section{Acknowledgements \\ None.}

\section{Funding}

AS is funded by a National Institute of Health Research Academic Clinical Fellowship. RV, AV, KK, MIJ, JA and NAS do not report any external funding.

\section{Availability of data and materials}

Raw data is not available for publication due to local restrictions from publishing potentially patient identifying data.

\section{Authors' contributions}

AS, RV, AV and KK collected and analysed the data. AS, RV and JA wrote the paper. MIJ, NAS and JA were involved in study design and reviewed the final manuscript.

\section{Ethics approval and consent to participate}

Local audit and research department approval was obtained (Newcastleupon-Tyne NHS Foundation Trust). Additional informed consent was not required for this retrospective study.

Consent for publication

Not applicable.

\section{Competing interests}

AS reports research grants from the National Institute of Health Research Academic Clinical Fellowship, Cancer Research UK and The Urology Foundation, for an unrelated project. RV, AV, KK, MIJ, JA and NAS have disclosed no conflicts of interest.

\section{Publisher's Note}

Springer Nature remains neutral with regard to jurisdictional claims in published maps and institutional affiliations.

Received: 17 May 2016 Accepted: 24 August 2017

Published online: 02 October 2017

\section{References}

1. Yossepowitch O, Briganti A, Eastham JA, Epstein J, Graefen M, Montironi R, Touijer K. Positive surgical margins after radical prostatectomy: a systematic review and contemporary update. Eur Urol. 2014;65(2):303-13.

2. Touijer K, Secin FP, Cronin AM, Katz D, Bianco F, Vora K, Reuter V, Vickers AJ, Guillonneau B. Oncologic outcome after laparoscopic radical prostatectomy: 10 years of experience. Eur Urol. 2009;55(5):1014-9.

3. Novara G, Ficarra V, Mocellin S, Ahlering TE, Carroll PR, Graefen M, Guazzoni G, Menon M, Patel VR, Shariat SF, et al. Systematic review and meta-analysis of studies reporting oncologic outcome after robot-assisted radical prostatectomy. Eur Urol. 2012;62(3):382-404. 
4. Mann MJ, DeCastro GJ, Desai M, Benson MC, McKiernan JM. Predictive significance of surgical margin status after prostatectomy for prostate cancer during PSA era. Urology. 2008;72(6):1203-7.

5. Pfitzenmaier J, Pahernik S, Tremmel T, Haferkamp A, Buse S, Hohenfellner M. Positive surgical margins after radical prostatectomy: do they have an impact on biochemical or clinical progression? BJU Int. 2008;102(10):1413-8.

6. Swindle P, Eastham JA, Ohori M, Kattan MW, Wheeler T, Maru N, Slawin K, Scardino PT. Do margins matter? The prognostic significance of positive surgical margins in radical prostatectomy specimens. J Urol. 2005;174(3):903-7.

7. Bolla M, van Poppel H, Tombal B, Vekemans K, Da Pozzo L, de Reijke TM, Verbaeys A, Bosset JF, van Velthoven R, Colombel M, et al. Postoperative radiotherapy after radical prostatectomy for high-risk prostate cancer: longterm results of a randomised controlled trial (EORTC trial 22911). Lancet. 2012;380(9858):2018-27.

8. Cornford P, Bellmunt J, Bolla M, Briers E, De Santis M, Gross T, Henry AM, Joniau S, Lam TB, Mason MD, van der Poel HG, van der Kwast TH, Rouvière O, Wiegel T, Mottet N. EAU-ESTRO-SIOG Guidelines on Prostate Cancer. Part II: Treatment of Relapsing, Metastatic, and Castration-Resistant Prostate Cancer. Eur Urol. 2017;71(4):630-42.

9. Gnanapragasam VJ, Thurtle D, Srinivasan A, Volanis D, George A Lophatananon A, Stearn S, Warren AY, Lamb AD, Shaw G, et al. Evolution and oncological outcomes of a contemporary radical prostatectomy practice in a UK regional tertiary referral centre. BJU Int. 2016;118(5):779-84.

10. Melia J, Moss S, Johns L. Contributors in the participating I: Rates of prostate-specific antigen testing in general practice in England and Wales in asymptomatic and symptomatic patients: a cross-sectional study. BJU Int. 2004;94(1):51-6.

11. Jemal A, Fedewa SA, Ma JM, Siegel R, Lin CC, Brawley O, Ward EM. Prostate Cancer Incidence and PSA Testing Patterns in Relation to USPSTF Screening Recommendations. Jama-J Am Med Assoc. 2015;314(19):2054-61.

12. Tewari A, Sooriakumaran $P$, Bloch DA, Seshadri-Kreaden U, Hebert AE, Wiklund P. Positive surgical margin and perioperative complication rates of primary surgical treatments for prostate cancer: a systematic review and meta-analysis comparing retropubic, laparoscopic, and robotic prostatectomy. Eur Urol. 2012;62(1):1-15.

13. Wright JL, Dalkin BL, True LD, Ellis WJ, Stanford $J$, Lange PH, Lin DW. Positive surgical margins at radical prostatectomy predict prostate cancer specific mortality. J Urol. 2010;183(6):2213-8.

14. Ficarra V, Novara G, Secco S, D'Elia C, Boscolo-Berto R, Gardiman M, Cavalleri S, Artibani W. Predictors of positive surgical margins after laparoscopic robot assisted radical prostatectomy. J Urol. 2009;182(6):2682-8.

15. Patel VR, Coelho RF, Rocco B, Orvieto M, Sivaraman A, Palmer KJ, Kameh D, Santoro L, Coughlin GD, Liss M, et al. Positive surgical margins after robotic assisted radical prostatectomy: a multi-institutional study. J Urol. 2011;186(2):511-6.

16. Sooriakumaran $\mathrm{P}$, Haendler L, Nyberg T, Gronberg H, Nilsson A, Carlsson S, Hosseini A, Adding C, Jonsson M, Ploumidis A, et al. Biochemical recurrence after robot-assisted radical prostatectomy in a European single-centre cohort with a minimum follow-up time of 5 years. Eur Urol. 2012;62(5):768-74.

17. Sukumar S, Rogers CG, Trinh QD, Sammon J, Sood A, Stricker H, Peabody JO, Menon M, Diaz-Insua M. Oncological outcomes after robot-assisted radical prostatectomy: long-term follow-up in 4803 patients. BJU Int. 2014; 114(6):824-31.

18. Abdollah F, Dalela D, Sood A, Sammon J, Jeong W, Beyer B, Fossati N, Rogers CG, Diaz-Insua M, Peabody J, et al. Intermediate-term cancer control outcomes in prostate cancer patients treated with robotic-assisted laparoscopic radical prostatectomy: a multi-institutional analysis. World Urol. 2016;

19. Laird A, Fowler S, Good DW, Stewart GD, Srinivasan V, Cahill D, Brewster SF, McNeill SA. British Association of Urological S: Contemporary practice and technique-related outcomes for radical prostatectomy in the UK: a report of national outcomes. BJU Int. 2015;115(5):753-63.

20. Dev HS, Wiklund P, Patel V, Parashar D, Palmer K, Nyberg T, Skarecky D, Neal DE, Ahlering T, Sooriakumaran P. Surgical margin length and location affect recurrence rates after robotic prostatectomy. Urol Oncol. 2015;33(3):109 e107-13.

21. Chalfin HJ, Dinizo M, Trock BJ, Feng Z, Partin AW, Walsh PC, Humphreys E, Han M. Impact of surgical margin status on prostate-cancer-specific mortality. BJU Int. 2012;110(11):1684-9.

22. Mauermann J, Fradet $V$, Lacombe L, Dujardin T, Tiguert R, Tetu B, Fradet $Y$. The impact of solitary and multiple positive surgical margins on hard clinical end points in 1712 adjuvant treatment-naive pT2-4 N0 radical prostatectomy patients. Eur Urol. 2013;64(1):19-25.

23. Sooriakumaran P, Srivastava A, Shariat SF, Stricker PD, Ahlering T, Eden CG, Wiklund PN, Sanchez-Salas R, Mottrie A, Lee D, et al. A multinational, multiinstitutional study comparing positive surgical margin rates among 22393 open, laparoscopic, and robot-assisted radical prostatectomy patients. Eur Urol. 2014;66(3):450-6.

24. Kang SG, Schatloff O, Haidar AM, Samavedi S, Palmer KJ, Cheon J, Patel VR. Overall rate, location, and predictive factors for positive surgical margins after robot-assisted laparoscopic radical prostatectomy for high-risk prostate cancer. Asian J Androl. 2016:18(1):123-8. doi: 10.4103/1008-682X.148723.

25. Wiegel T, Bottke D, Steiner U, Siegmann A, Golz R, Storkel S, Willich N, Semjonow A, Souchon R, Stockle M, et al. Phase III postoperative adjuvant radiotherapy after radical prostatectomy compared with radical prostatectomy alone in pT3 prostate cancer with postoperative undetectable prostate-specific antigen: ARO 96-02/AUO AP 09/95. J Clin Oncol. 2009;27(18):2924-30.

26. Koulikov D, Mohler MC, Mehedint DC, Attwood K, Wilding GE, Mohler JL. Low detectable prostate specific antigen after radical prostatectomy-treat or watch? J Urol. 2014;192(5):1390-6.

27. Swanson GP, Hussey MA, Tangen CM, Chin J, Messing E, Canby-Hagino E, Forman JD, Thompson IM, Crawford ED. Swog: Predominant treatment failure in postprostatectomy patients is local: analysis of patterns of treatment failure in SWOG 8794. J Clin Oncol. 2007;25(16):2225-9.

28. Savdie R, Horvath LG, Benito RP, Rasiah KK, Haynes AM, Chatfield M, Stricker PD, Turner JJ, Delprado W, Henshall SM, et al. High Gleason grade carcinoma at a positive surgical margin predicts biochemical failure after radical prostatectomy and may guide adjuvant radiotherapy. BJU Int. 2012;109(12):1794-800

29. Straub B, Muller M, Krause H, Goessl C, Schrader M, Heicappell R, Miller K. Molecular staging of surgical margins after radical prostatectomy by detection of telomerase activity. Prostate. 2001;49(2):140-4.

30. Theodorescu D, Frierson HF Jr, Sikes RA. Molecular determination of surgical margins using fossa biopsies at radical prostatectomy. J Urol. 1999:161(5):1442-8.

31. Mao L, Clark D. Molecular margin of surgical resections-where do we go from here? Cancer-Am Cancer Soc. 2015:121(12):1914-6.

32. Boorjian SA, Karnes RJ, Crispen PL, Carlson RE, Rangel LJ, Bergstralh EJ, Blute $\mathrm{ML}$. The impact of positive surgical margins on mortality following radical prostatectomy during the prostate specific antigen era. J Urol. 2010;183(3):1003-9.

33. Evans SM, Millar JL, Frydenberg M, Murphy DG, Davis ID, Spelman T, Bolton DM, Giles GG, Dean J, Costello AJ, et al. Positive surgical margins: rate, contributing factors and impact on further treatment: findings from the Prostate Cancer Registry. BJU Int. 2014;114(5):680-90.

\section{Submit your next manuscript to BioMed Central and we will help you at every step:}

- We accept pre-submission inquiries

- Our selector tool helps you to find the most relevant journal

- We provide round the clock customer support

- Convenient online submission

- Thorough peer review

- Inclusion in PubMed and all major indexing services

- Maximum visibility for your research

Submit your manuscript at www.biomedcentral.com/submit
) Biomed Central 